\begin{tabular}{|c|c|c|}
\hline $\begin{array}{l}\text { PKS } \\
\text { PUBLIC } \\
\text { KNOWLEDGE } \\
\text { PROJECT }\end{array}$ & $\begin{array}{c}\text { Revista de GEOGRAFIA } \\
\text { (RECIFE) } \\
\text { http://www.revista.uffe.br/revistageografia }\end{array}$ & $\begin{array}{l}\text { OJS } \\
\frac{\text { OPEN }}{\text { JOURAL }} \\
\text { SYSTEMS }\end{array}$ \\
\hline
\end{tabular}

\title{
O FILME ENQUANTO GEOGRAFIA: PROPOSIÇÕES E INSIGHTS INICIAIS
}

\author{
Francyjonison Custódio do Nascimento ${ }^{1}$ \\ ${ }^{1}$ Doutorando em Geografia na Universidade Federal do Rio Grande do Norte. \\ Email: jonisoncustodio@hotmail.com
}

Artigo recebido em 25/08/2017 e aceito em 01/10/2017

\begin{abstract}
RESUMO
$\mathrm{Na}$ busca do diálogo entre ciência e arte, este artigo, parte de uma pesquisa de Doutorado em andamento, trata da relação entre Geografia e Cinema a partir do diálogo com os pressupostos teórico-metodológicos, os quais visam extrapolar o entendimento do cinema como uma noção mimética da realidade. Partindo-se da ontologia geográfica de Eric Dardel, concebe-se, então, o filme como uma geografia, entendendo que esta é uma maneira de falar sobre a experiência humana sobre a Terra. Chega-se à conclusão que a experiência terrestre não se resume a aspectos racionais, mas é transpassada também pela imaginação e por comunhões, sejam elas espirituais-míticas ou emocionais; relevando a pertinência de se trabalhar com filmes de teor onírico.
\end{abstract}

Palavras-chaves: Abordagem cultural. Geografia e Cinema. Ontologia da Geografia. Eric Dardel.

\section{THE FILM AS GEOGRAPHY: INITIAL PROPOSITIONS AND INSIGHTS}

\begin{abstract}
In the search for a dialogue between science and art, this article, part of an ongoing research, approaches the relationship between Geography and Cinema from the dialogue with theoretical and methodological assumptions, which aim to extrapolate the understanding of cinema as a mimetic notion of reality. Starting from the geographic ontology of Eric Dardel, the film is conceived as a geography, understanding that this is a way of talking about the human experience on Earth. It comes to the conclusion that the human experience on Earth is not limited to rational aspects, but is also pierced by the imagination and communions, be they spiritual-mythical or emotional; highlighting the pertinence of working with films with an imaginary content.
\end{abstract}

Keywords: Cultural approach. Geography and Cinema. Geography ontology. Eric Dardel. 


\section{INTRODUÇÃO}

A ciência geográfica, no entendimento de sua abordagem cultural, é uma indagação sobre um modo de falar acerca do mundo. Em outras palavras: fazer Geografia é interrogar-se sobre o modo de ser e estar no mundo. Nesse entendimento, portanto, a Geografia deve se preocupar com a experiência humana sobre a Terra e todos os modos possíveis de falar dessa experiência. Assim, todos os recursos utilizados para falar da experiência terrestre são importantes para os geógrafos.

Tais pressupostos possuem um corolário: já não há motivos para perpetuar uma hierarquização dos diferentes modos de dizer o mundo, como postulou o ideário modernista no qual a ciência era o único meio de veiculação do conhecimento. A Literatura, o Cinema, a Fotografia: todas essas realidades possuem uma geograficidade, revelam um modo de ser e estar no mundo. Desse modo, Geografia e as diversas linguagens artísticas possuem uma relação intrínseca.

O Cinema e a Geografia, contudo, vão além dessa relação. Mais do que dialogar vividamente, eles se confundem, posto que o Cinema é também uma Geografia, um modo de dizer o mundo, uma grafia do pensamento espacial. É por este motivo que, neste projeto, se propõe o Cinema como uma grafia imaginativa de um pensamento espacial. Daí a pertinência de estudar o Cinema como área de conhecimento que influencia na construção e percepção do mundo, permeado pelo imaginário e pelo simbólico.

Os estudos que envolvem o Cinema e a Geografia bem como as outras ciências sociais também são pertinentes, pois vivemos num mundo no qual as relações de todo o gênero incluindo as espaciais - são mediadas por uma cultura visual. As diversas experiências e relações geográficas são mediadas, portanto, por uma tela, por um écran. O Cinema é uma das maiores manifestações dessa cultura visual ou, quiçá, a maior deles.

Partindo desses pressupostos, propõe-se o espaço fílmico como campo de trabalho. Além da já citada aproximação entre a Geografia e a Arte bem como a geograficidade presente nos diversos elementos das mídias imagéticas, outro motivo impele a tal proposta: o fato do Cinema, através de filmes, auxiliar na apropriação dos espaços e na reordenação das imaginações geográficas, pois ele produz conhecimentos de ordem geográfica uma vez que é um objeto imbuído de discursos espaciais. De fato, durante as últimas décadas, após o “cultural turn", as obras fílmicas têm ganhado destaque nas análises geográficas sobretudo na abordagem cultural da Geografia, mas com os neomarxistas também. 
Dentro desse contexto, esse artigo é composto das discussões realizadas no início do projeto de doutorado ${ }^{1}$. Esse projeto pretende analisar os filmes que passam na Terra-Média, a trilogia $O$ Senhor dos Anéis. Vários motivos nos impulsionam a ter esses filmes como objetos de análise. A Trilogia é um marco do cinema contemporâneo e não somente pelo fato de ter ganhado 17 estatuetas do Oscar, a mais famosa premiação do Cinema, e ter uma grande audiência. O grande destaque deve-se à natureza dos filmes. Devido ao desenvolvimento tecnológico, somente a pouco tempo, pode-se construir, no Cinema, mundos completamente novos, mundos imaginários devido ao uso de efeitos especiais. Assim, o Cinema contemporâneo é marcado por esse teor onírico, no qual o imaginário é uma das principais características. A trilogia $O$ Senhor dos Anéis foi um dos primeiros filmes com esse aspecto e, de certo modo, inaugura esse novo tempo.

Para o melhor entendimento, é necessário discorrer sobre as obras. Elas são resultado de traduções de livros de J.R.R. Tolkien, famoso escritor inglês de literatura fantástica; se enquadrando, assim, nos gêneros de Fantasia e Aventura. Os filmes foram produzidos e dirigidos por Peter Jackson, com a distribuição pela Warner Bros. Entertainment. As locações foram realizadas, inteiramente, na Nova Zelândia, tanto as sequências externas e como os sets de filmagem. Os filmes narram a estória de uma comitiva que deveria deixar o tranquilo e bucólico Condado, região que fica a oeste da Terra-Média (um continente do mundo fantástico onde a história se passa) em direção ao Sudeste, para Mordor, a Terra do Senhor do Escuro, afim de destruir um poderoso artefato que mobiliza toda a trama do filme, o Um Anel. Ao longo da jornada, os membros da comitiva passam por diversos lugares, manifestando, assim, algo que está presente em toda a narrativa: a noção de que cada ser se relaciona com o espaço a sua maneira. É notável como cada membro da comitiva regiões bucólicas e campestres, regiões de floresta, regiões de caráter urbano, entre outras.

Diante disso, esse artigo, como parte dessa pesquisa de Doutorado, intenta discutir sobre a geografia e cinema. Para tanto, se utilizará de uma revisão bibliográfica de autores que pensam essa relação como também de autores que pensem a ontologia da geografia.

\section{GEOGRAFIA E CINEMA}

A abordagem cultural da Geografia postulou, com uma reviravolta das matrizes da ciência geográfica após a década de 1970, um novo olhar sobre o diálogo com as linguagens

\footnotetext{
${ }^{1}$ Doutorado iniciado em 2017, sob a orientação da Prof ${ }^{a} \operatorname{Dr}^{a}$ Maria Helena Braga e Vaz da Costa. 
artísticas. Na verdade, a Geografia sempre se utilizou dessas linguagens, mas era numa perspectiva meramente "comprobatória". Ou seja, tanto as linguagens de cunho visual (pinturas, fotografias e, mais tarde, os filmes) como a Literatura eram usadas para confirmar os estudos geográficos realizados anteriormente e não eram em si mesmas fontes de preocupação dos geógrafos (AZEVEDO, 2009).

Com as novas abordagens da metade do século XX, os conceitos geográficos passaram a ser compreendidos sob uma perspectiva nova, com um caráter simbólico e subjetivo. Os geógrafos que comungavam com essas novas perspectivas tinham a intenção de romper com o caráter (neo)positivista da Geografia ao enfatizar valores humanistas com base em filosofias do significado (a Fenomenologia e o Existencialismo), posto que, no entendimento deles, o Positivismo não explicava mais a realidade frente à diversidade social e cultural do mundo.

Para esses geógrafos, a Arte é primordial, pois ela é agente nas interpretações das culturas em sua inscrição espacial, capacitando o geógrafo a reunir o maior número de elementos no que se refere a valores e significações. Ou, nas palavras do autor, "aquilo que a ciência não chega reconhecer, devido aos limites impostos pelo método, a arte o consegue por um meio não-racional.” (GOMES, 2010, p. 314).

Assim sendo, a Arte faria aquilo que a Ciência não conseguiria fazer: ser elemento de mediação entre a vida e o universo das representações. De fato, como nos lembra Claval: "em todos os domínios, são os artistas que servem de mestres ao geógrafo" (CLAVAL, 2014, p. 230). Com efeito, na Geografia, essa aproximação com a Arte cresceu exponencialmente e as obras fílmicas têm ganhado destaque nas análises geográficas. Nessas últimas, apesar de sua relativa atualidade, inúmeros são os trabalhos e os pesquisadores que tomam para si os filmes como objetos de análise.

Esse destaque nos estudos das geografias fílmicas, além do diálogo entre a Geografia e as diversas linguagens artísticas, foi acentuado na contemporaneidade por outro motivo: vivenciamos aquilo que Lipovetsky e Sorry (2009) chamam de tela global, que, por sua vez, proporciona uma cinevisão. Segundo os autores, atualmente, as nossas relações com o mundo e com os outros são cada vez mais mediatizadas por écrans, por interfaces nas quais as telas não cessam de se comunicar. Há, então, uma ecranfilia; um reino das telas em nossas relações. Isto proporciona uma cinevisão ou uma cinematografização do mundo, na qual o cinema molda a nossa forma de ver o mundo.

De fato, "o Cinema tornou-se formador de um olhar global dirigido às esferas mais diversas da vida contemporânea" (LIPOVETSKY; SERROY, 2009, p. 29). As nossas 
relações com o espaço também estão imersas nesse mundo de mediação imagética; há, portanto, uma geograficidade mediatizada. Daí a necessidade de pensar os conceitos geográficos permeados e (re)construídos por ordem imagética. Essa ordem media as relações com mundo atualmente e o cinema é prova disso, posto que é uma das geografias imaginativas mais poderosas do nosso tempo, pois contribui para uma "narrativazação" dos espaços mediante uma linguagem, a linguagem da paisagem (AZEVEDO, 2006).

Na contemporaneidade também, explicam Lipovetsky e Sorry (2009), vivemos, no Cinema, o advento de mundos oníricos, graças aos avanços tecnológicos. Esses últimos não só proporcionaram retoques em imagens ou inserir atores em ambientes virtuais, mas é responsável por instituir terras fantásticas, como a Terra-Média, o mundo de $O$ Senhor dos Anéis; contempla-se, assim, a imensidão dos territórios do fantástico, do feérico (LIPOVETSKY; SERROY, 2009).

Maffesoli (2014) comenta também como este tempo é marcado pela volta da imaginação. $\mathrm{O}$ imaginário está em todos os setores da sociedade atual, a qual já rejeitou o ideal da modernidade e sua completa racionalização da existência. A imaginação, outrora “inútil”, já não está à beira do caminho, mas, junto com as comunhões emocionais, formam o âmago do que o autor francês chama de razão sensível, uma razão que não nega os sentimentos tampouco o mundo onírico. O imaginário é, portanto, uma constante na sociedade e que, além disso, emite discursos e formas de se relacionar com o mundo.

$\mathrm{Na}$ Geografia, esse processo não é muito distinto, apesar de mais tímido. Lowenthal (1982) chamou atenção, há décadas, do valor da imaginação nos estudos das experiências geográficas e, de certa forma, incita a sua inclusão no seio da ciência geográfica. Antes de Lowenthal (1982), Wright (2014), elucidava a importância de "valorizar a imaginação e a subjetividade como qualidades fundamentais para um bom geógrafo, e para uma ciência mais clara, viva, condizente com a realidade da vida." (WRIGHT, 2014, p. 4). Para ele, uma forte desconfiança para com o uso da imaginação pelos geógrafos era nociva, pois reprimia os impulsos artísticos e poéticos dos geógrafos, fazendo-os prosaicos e tornando-os encrustados em tudo no domínio da ciência geográfica.

No entendimento de Wright (2014), portanto, a Geografia, como era comum na sua época, não podia negligenciar a imaginação e deixá-la, apenas, aos cuidados dos artistas, poetas e filósofos. Wright (2014) invoca a imaginação e a abertura a esta para os trabalhos geográficos como um remédio contra as pesquisas meramente objetivas, utilitárias. Além de tudo isso, há outro aspecto em Wright (2014) que merece destaque. Para ele, a fantasia e a 
imaginação não nos conduz ao erro. É preciso recordar que há uma diferença entre fantasia e ilusão. A fantasia não é meramente ilusória; ela nos conduz, também, a verdades. No seu entendimento,

\begin{abstract}
Não somos, de maneira alguma, iludidos por todas as nossas fantasias. Escritores frequentemente criam fantasias para o objetivo específico de fazer a exposição de suas verdades da maneira mais eficiente possível. Isso pode ser feito [...] através da escrita de romances e poemas épicos inteiros. (WRIGHT, 2014, p. 11)
\end{abstract}

Assim, as fantasias não significam necessariamente irracionalidades; elas podem nos munir de verdades, de modos de pensar sobre determinado assunto. De fato, o imaginário não depaupera ou tampouco aniquila o olhar sobre o mundo, muito menos o deforma, porque constitui uma totalidade que cria o sentido e a própria existência - dado que essa se dá na experiência; auxilia, assim, na compreensão do mundo (MACIEL, 2002).

Os geógrafos, portanto, não pode negligenciar completamente esse olhar, pois elas não excluem a possibilidade de construir um trabalho cientifico, como postulavam alguns contemporâneos de Wright. Utilizá-las e tê-las como objeto de estudo, assim, se evidencia como importante para a ciência geográfica. Outros autores que pensam a ciência geográfica também possuem o mesmo entendimento sobre a pertinência da imaginação, tais como Hissa (2006), Besse (2006), Marandola (2010), Claval (2010) e Mello (2012). E, ao apontar a importância da imaginação, esses mesmos autores também a vinculam às linguagens artísticas. Este projeto se baseia nisso ao pensar na tríade Geografia-Cinema-Imaginação.

Tal concepção nos faz pensar o Cinema não apenas enquanto um objeto que pode promover um diálogo com a ciência geográfica, mas, mais do que isso, como uma geografia. Wright (2014) fala de uma geografia informal; Azevedo (2009), de uma geografia imaginativa e Oliveira Junior (2012), de uma geografia menor ou de uma grafia de um pensamento espacial. Neste projeto, combinando esses entendimentos, se propõe o Cinema como uma grafia imaginativa de um pensamento espacial.

Isso porque vamos além do pensamento de Oliveira Junior (2012) e pensamos que o espaço fílmico não é somente alusão dos lugares geográficos, mas um discurso sobre o lugar geográfico. Muito mais do que falar sobre o espaço geográfico, o filme fala sobre o entendimento do homem sobre o espaço; é assim um modo de apresentar um pensamento espacial, um discurso geográfico. Assim, não se intentará comparar o espaço fílmico com o espaço além-filme, mas encontrar, no primeiro, discursos a respeito do segundo. 
De fato, o próprio Oliveira Junior (2012) e outros autores, como Name (2013) e, reconhecem que há no mundo atual, uma gama de objetos de ordem imagéticas, tendo o Cinema uma proeminência, que falam sobre o espaço e das formas como o homem habita e pensa esse mesmo espaço. Oliveira Junior (2012), se baseando em Doren Massey, chama essa forma de pensar o espaço de imaginação geográfica; Name (2013), de discursos geohistóricos. Prefere-se aqui, por opção epistemológica, o termo discursos espaciais, pois pensase, com Metz (1980), que o Cinema é um emissor de discurso bem como por compreender que o termo imaginação é mais complexo do que a noção supracitada.

Toda essa argumentação sobre a necessidade da imaginação para uma geografia mais vivida e da pertinência de se enveredar pelos caminhos da ordem imagética só tem sentido se partem de um pressuposto: a geografia é uma forma de falar a experiência de ser e estar no mundo. E mais do que isso: por ser esse questionamento/discurso sobre o mundo, é, antes de uma ciência, uma experiência da existência humana. Berdoulay (2003), seguindo essa senda, explica que a geografia é "um relato da experiência do homem tentando explicar o mundo" (BERDOULAY, 2003, p. 47).

Isto é, a geografia é um relato, uma narrativa. Os geógrafos se utilizam de várias ferramentas, discursos orais e escritos, cartas, croquis, fotografias e - lógico! - filmes para tornar viva a descrição e explicação do mundo. Essa perspectiva é, sem dúvida, tributária do pensamento de Eric Dardel sobre a geografia. Segundo a ontologia dardeliana da geografia, antes do geógrafo há sempre um homem que vive, experimenta o mundo. Dardel, assim, prioriza a relação do homem com o mundo e faz mais do que retomar a posição da geografia clássica vidaliana, lhe dá uma fundamentação ontológica, vinculada ao ser.

Essa concepção advém da compreensão de que o espaço geográfico não é um espaço abstrato, neutro. Para pensar a geografia, Dardel (2015) opõe o espaço geográfico ao espaço geométrico, a geografia a geometria. O espaço geométrico é neutro e uniforme; é vazia de conteúdo, um espaço abstrato. Por isso, está, ou melhor, é disponível para qualquer tipo de combinação. É a concepção newtoniana de espaços comentada por Gomes (2010), um espaço no qual é possível encaixar peças, tirar ou remover como tabuleiro de xadrez. O espaço geográfico, por sua vez, não é neutro. Ele tem um horizonte, cor, uma modelagem, um desenho.

Na perspectiva dardeliana, explica Holzer (2014), essa oposição é essencial. Desse modo, o espaço geométrico estava ligado a espacialidade, aos conceitos e modelos do espaço utilizados para o ordenamento dele ao passo que o espaço geográfico tem um caráter 
ontológico, está vinculado a geograficidade, ao aspecto existencial do ser humano. Essa concepção de espaço geográfico é vital para a pensar a concepção de geografia de Eric Dardel. Sem ela, não haveria motivos para reconstruir uma nova visão da disciplina, pois a concepção anterior bastaria. A ciência positivista daria conta do espaço do geômetra, do homem que calcula e mede o espaço.

É repensando a noção de espaço geográfico que Dardel propõe essa ontologia geográfica, que funda essa geografia que, atualmente, podemos chamar de fenomenológicaexistencial. Se o espaço geográfico não é neutro; é um desenho e, por isso, tem cor e intensidade, somente um novo entendimento sobre a geografia daria conta de compreender o espaço.

A geografia de Eric Dardel, então, numa retomada a Geografia Clássica, está baseada na descrição da terra. Contudo, Dardel (2015) dá, influenciado pelas filosofias do significado, ênfase não apenas na descrição, mas na leitura - muitas vezes, hermenêutica - da fisionomia da terra, ou melhor, dos signos que compõem a superfície terrestre. Nas palavras do autor francês, a geografia “é, segundo a etimologia, a 'descrição' da Terra; mais rigorosamente, o termo grego sugere que a Terra é um texto a decifrar" (DARDEL, 2015, p. 2). Assim, todas as sinuosidades da superfície terrestre seriam signos desse texto. Desse modo,

O conhecimento geográfico tem por objeto esclarecer esses signos, isso que a Terra revela ao homem sobre sua condição e seu destino. Não se trata, inicialmente, de um atlas aberto diante dos olhos, é um apelo que vem do solo, da onda, da floresta, uma oportunidade ou uma recusa, um poder, uma presença. (DARDEL, 2015, p. 2).

Em suma, a Terra seria um texto e a geografia uma forma de decifrar esse texto. A própria etimologia da palavra geografia proporciona esse entendimento. Partindo da premissa de que a terra é um texto e a geografia uma interpretação desse texto, ou seja, uma maneira de ler o mundo, pode-se, naturalmente, comparar o fazer do geógrafo com o do hermeneuta: analisar, interpretar textos. O geógrafo é um leitor do mundo e daí o corolário de compreender a geografia como uma maneira de falar sobre o mundo.

Tal postura foi essencial (e ainda é), pois se opõe a geografia científica que estava em vigor no século XIX e apenas se propunha calcular e medir, negligenciando a interpretação ontológica da Terra. Essa geografia positivista e objetiva, a geografia de gabinete, não alcança a completude da relação do homem com o mundo, com a Terra. Essa concepção, então, 
aviltava a complexidade da geografia ao comprometer aquilo que é, na perspectiva existencial, um dos aspectos constitutivos do ser humano: sua relação com o espaço.

Na perspectiva dardeliana, a geografia, como já dito, não é apenas um conhecimento referido a um objeto especifico, mas uma ciência que intenta explicar o mundo, de compreender o mundo geograficamente. Daí a concepção de que toda e qualquer forma de explicar o mundo é uma geografia. Daí surge o insight que provocou esse texto: já que o filme é uma forma de narrar a experiência humana sobre a Terra não seria ele, então, uma geografia?

\section{CONSIDERAÇÕES FINAIS}

O presente trabalhou abordou a relação entre Geografia e Cinema a partir do diálogo com os pressupostos teórico-metodológicos que visam extrapolar o entendimento do cinema como uma noção mimética da realidade. Ainda que essa compreensão sobre os filmes possa parecer ser útil em análises geográficas, ela castra toda a potencialidade do filme ao reduzir sua capacidade de apresentar novas maneiras de falar sobre o mundo e o espaço e, o que seria mais problemático, elucida uma visão neutra da obra cinematográfica. Além disso, percebeuse como o filme é um discurso que está vinculado a uma forma de ver e viver o mundo - uma geografia! - dentre tantas outras formas. Assim, fez-se apontamentos que se pode levar a conclusão de que o filme é sempre uma geografia.

Abordou-se, também, a pertinência de estudar os espaços imaginários, reconhecendo que o teor onírico do qual o cinema contemporâneo é permeado não avilta um olhar acurado sobre a realidade, mas, de certa forma, o sublima ao tentar restaurar a experiência integral do homem com mundo que não se resume apenas aos aspectos racionais, mas é transpassada também pela imaginação e por comunhões, sejam elas espirituais-míticas ou emocionais.

Esse trabalho é apenas um ponta-pé inicial, um vislumbre do que há de vir na pesquisa que se inicia. Os pressupostos e insights aqui elucidados apontam para um caminho, mas, ao se enveredar pela geografia da fantasia, quase nunca se sabe onde se vai chegar. A única certeza é que, avançando neste caminho e deixando para trás as fronteiras rígidas da ciência paralisante e alienada, adoradora cega da deusa Razão, pode-se chegar na essência da experiência humana sobre a Terra e, verdadeiramente, vislumbrar o caleidoscópio excitante da geografia que se reconhece plural; que nada nega e tudo abraça com a finalidade de estudar as inúmeras maneiras de como o ser humano se relaciona com a Terra, com o mundo. 


\section{REFERÊNCIAS}

AZEVEDO, Ana Francisca. Geografia e cinema: representações culturais de espaço lugar e paisagem na cinematografia portuguesa. 2007. 741 f. Tese (Doutorado em Geografia) Universidade do Minho.

Geografia e cinema. In: CORRÊA, Roberto Lobato e ROSENDHAL, Zeny (Org.).

Cinema, Música e Espaço. Rio de Janeiro: EdUERJ, 2009.

BERDOULAY, Vicent. A abordagem contextual. Espaço e Cultura, UERJ, Rio de Janeiro, n. 16, jul/dez. 2003.

BESSE, Jean-Marc. Ver a Terra: seis ensaios sobre a paisagem e a geografia. São Paulo: Perspectiva, 2006.

O Gosto do Mundo: exercícios de paisagem. Rio de Janeiro: EdUERJ, 2014.

CLAVAL, Paul. Epistemologia da Geografia. Florianópolis: Editora da UFSC, 2014.

CostA, M. H. B. V.. Geografia Cultural e Cinema: Práticas, Teorias e Métodos. In: ROSENDAHL, Zeny; CORRÊA, Roberto Lobato. (Org.). Geografia: temas sobre Cultura e Espaço. Rio de Janeiro: EDUERJ, v., p. 43-78, 2005.

DUNCAN, James S. A paisagem com sistema de criação de signos. In: CORREAA, Roberto Lobato; ROSENDAHL, Zeny (Org.). Paisagens, textos e identidade. Rio de Janeiro: Eduerj, 2004.

GOMES, Paulo Cesar da Costa. Geografia e Modernidade. $8^{\mathrm{a}}$ ed. Rio de Janeiro: Bertrand Brasil, 2010.

HISSA, Cássio E. Viana. A mobilidade das fronteiras: inserções da Geografia na crise da modernidade. Belo Horizonte, Editora UFMG, 2006.

HOLZER, Werther. Mundo e lugar: ensaio de geografia fenomenológica. In: MARANDOLA JR., Eduardo; HOLZER, Werther; OLIVEIRA, Lívia (orgs). Qual o espaço do lugar: Geografia, Epistemologia, Fenomenologia. São Paulo: Perspectiva, 2014.

LIPOVETSKY, Gilles; SERROY, Jean. A tela global: mídias culturais e cinema na era hipermoderna. Porto Alegre: Sulina 2009.

LOWENTHAL, David. Geografia, experiência e imaginação: em direção a uma epistemologia geográfica, 1960. In: CHRISTOFOLETTI, Antônio (org). Perspectivas da Geografia. São Paulo: Difel, 1982.

MACIEL, C. A. A. Morfologia da paisagem e imaginário geográfico: uma encruzilhada ontognoseológica. In: GEOgraphia, UFF. Ano 3, n. 6. Niterói, RJ, 2002 
MARANDOLA. Eduardo; GRATÃO, Lúcia Helena Batista (Orgs.). Geografia e literatura: ensaios sobre geograficidade, poética e imaginação. Londrina: EDUEL, 2010.

MELLO, J. B. F. de. O triunfo do lugar sobre o espaço. IN: MARANDOLA JR., Eduardo; HOLZER, Werther; OLIVEIRA, Lívia de (Orgs.). Qual o Espaço do Lugar? Geografia, Epistemologia, Fenomenologia. São Paulo: Perspectiva, 2012.

METZ, Christian. Linguagem e cinema. Tradução de Marilda Pereira. São Paulo: Perspectiva, 1980.

NAME, Leonardo. Geografia pop: o cinema e o outro. Rio de Janeiro, Apicuri: 2013.

OLIVEIRA JUNIOR, W. .IN: MARANDOLA JR., Eduardo; HOLZER, Werther; OLIVEIRA, Lívia de (Orgs.). Qual o Espaço do Lugar? Geografia, Epistemologia, Fenomenologia. São Paulo: Perspectiva, 2012.

WRIGHT, Jonh K.. Terrae Incognitae: o lugar da imaginação na Geografia. Geograficidade, v.4, n.2, Inverno, 2014. 